\title{
Modification and Upgrade of AzRISE/TEP Solar Photovoltaic Test Yard
}

\author{
Whit Bennett, Asher Fishgold, Teh Lai, Teri Elwood, Barrett G. Potter, Jr. \\ and Kelly Simmons-Potter \\ University of Arizona, Tucson, AZ 85721
}

\begin{abstract}
The University of Arizona AzRISE (Arizona Research Institute for Solar Energy) and Tucson Electric Power solar test yard is currently undergoing renovations to upgrade and standardize the data acquisition capabilities throughout the yard. Test yard improvements have enabled increased data collection reliability through state-of-the-art and environmentallyrobust data logging and real-time analysis. Enhanced capabilities include $10 \mathrm{msec}$ max. data resolution, precision PV backside temperature monitoring of both individual and strings of modules, measurement of both AC and DC outputs as well as GHI and POA irradiance, active data backup to eliminate data intermittency, and robust Ethernet connectivity for data collection. An on-site weather station, provides wind speed and direction, relative humidity, and air temperature data. The information collected is accessed remotely via web server and includes raw performance and environmental conditions as well as extracted figures of performance for systems under test. Complementing the UA's existing accelerated environmental-testing chamber, the new test yard acquisition capabilities have enabled high fidelity system and sub-system-level operational testing under a range of field-level test conditions. The combined facilities, thus, provide a full-spectrum testing resource for photovoltaic performance and degradation analysis. Specific measurement characteristics and sample data collected from a polysilicon module test string are utilized to illustrate test yard capabilities.
\end{abstract}

Keywords: photovoltaic, test yard, reliability, lifecycle test, environmental degradation, data logger, solar

\section{INTRODUCTION}

In 2007, as part of a collaboration between the University of Arizona's Arizona Research Institute for Solar Energy (AzRISE) and Tucson Electric Power (TEP) to provide a field-relevant photovoltaic system test facility, the AzRISE/TEP Photovoltaic Test Yard was established. The facility, located in Tucson, AZ, provides instrumented space with centralized weather and PV data collection. The site has served as an enabling test location in support of TEP's solar energy generation implementation plan as well as for characterization and evaluation projects involving solar energy manufacturers and academic researchers ${ }^{[1-3]}$. Outdoor testing facilities such as this are essential to understanding the anticipated performance of photovoltaic modules under field-consistent environments ${ }^{[3-7]}$ that extend beyond those used in standard test conditions (STC); the latter do not take into account location-dependent temperature and humidity climates, shading, atmospheric conditions, or soiling. Moreover, the data from the test yard can provide additional insight into the validity of laboratory-based performance measurements ${ }^{[8]}$. In this context, the test yard has been used to validate UA's accelerated test protocols, which can model a year's worth of environmental data in roughly three and a half months ${ }^{[3,8]}$.

With an increase in interest in the test yard, a comprehensive upgrade of data collection and storage capability and broadband access have been instituted. This effort moves forward in conjunction with a complete refurbishment of PV system monitoring infrastructure and electronics, providing an expandable and robust measurement architecture offering real-time remote access to data streams for users. The successful reestablishment of the test yard offers manufacturers,

Reliability of Photovoltaic Cells, Modules, Components, and Systems IX, edited by Neelkanth G. Dhere, John H. Wohlgemuth, Keiichiro Sakurai, Proc of SPIE Vol. 9938, 99380S · (c) 2016 SPIE CCC code: $0277-786 X / 16 / \$ 18 \cdot$ doi: $10.1117 / 12.2238187$ 
installers, operators, and researchers an open environment for new and established technology testing and qualification. The present work provides an overview of site improvements and enhanced capabilities. Preliminary test results highlighting data collection fidelity and consistency are also provided.

\section{TEST YARD LAYOUT AND INSTRUMENTATION URGRADES}

The solar test yard is located at 4350 E. Irvington Rd. in Tucson, Arizona, on the main TEP campus. The facility has been subdivided into five zones based on physical location, electrical line routing, and the location of common junction boxes. Special precautions have been implemented in the test yard design to separate power and data lines through individual conduit in order to minimize crosstalk. Figure 1 shows a side view of a several strings of mounted modules within the test yard.

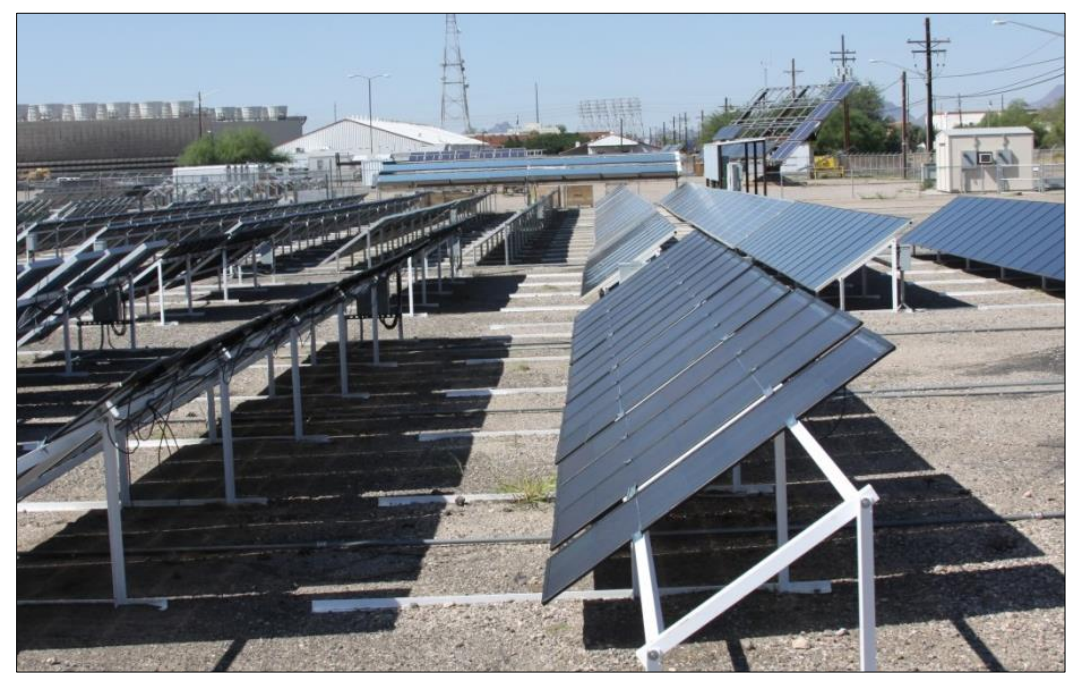

Figure 1: Image of several module strings in the AzRISE/TEP test yard.

In the present paper, data collected from Zone 1 of the yard will be presented to highlight the impact of the implemented data collection and PV sensor improvements. Figure 2 shows an image of the yard with Zone 1 emphasized (located in the lower right quadrant of the image (SE corner of the test yard)).

Legacy instrumentation at the AzRISE/TEP test yard presented a variety of challenges, including data intermittency, lack of power and data backup, temperature instability, and AC/DC signal crosstalk. Implemented upgrades have focused on utilizing robust, environmentally-stable data logging and sensor devices, developing both power and data backup systems, and eliminating cross-talk through signal segregation. Given the extreme temperatures characteristic of southern Arizona, an additional key priority was thermal stability of all test instrumentation in order to minimize the potential for error, noise and/or data failure during testing. In addition, the test yard is subject to frequent AC power interruptions, particularly during summer monsoons, so independent backup power configurations were also important in the upgrade design.

Toward those ends, legacy Lab Jack data loggers, operating on Lab View software were replaced with Campbell Scientific data loggers (CR1000 and CR3000) with multiplexer channel extenders. While reliable laboratory instruments, the Lab Jack data loggers were not developed for operation in extreme outdoor environments. The loggers 
themselves were not equipped with battery backup or with memory storage to provide local data backup. In addition, the legacy design did not include any failure detection system such that communication interruptions between data loggers and acquisition software were only identifiable through direct, physical inspection. As such, data gaps and intermittency were common occurrences.

The implementation of CR1000/3000 data loggers offers many advantages over the legacy system. Specifically, the data loggers have a stable operational temperature range of $-55^{\circ}$ to $85^{\circ} \mathrm{C}$, have been equipped with battery backup, have 4 $\mathrm{Mb}$ of onboard memory for data storage, can be operated with multiplexer channel extenders to increase the number of accessible signal inputs, and support a broad range of environmentally-robust third-party voltage, current, and temperature sensors. The equipment uses LoggerNet, software for its operation, which works essentially like Lab View, but allows for greater mapping and a universal clock for all data acquisition. This allowed for all measurements to share a time stamp throughout the test yard since all devices were able to communicate with the central hub.

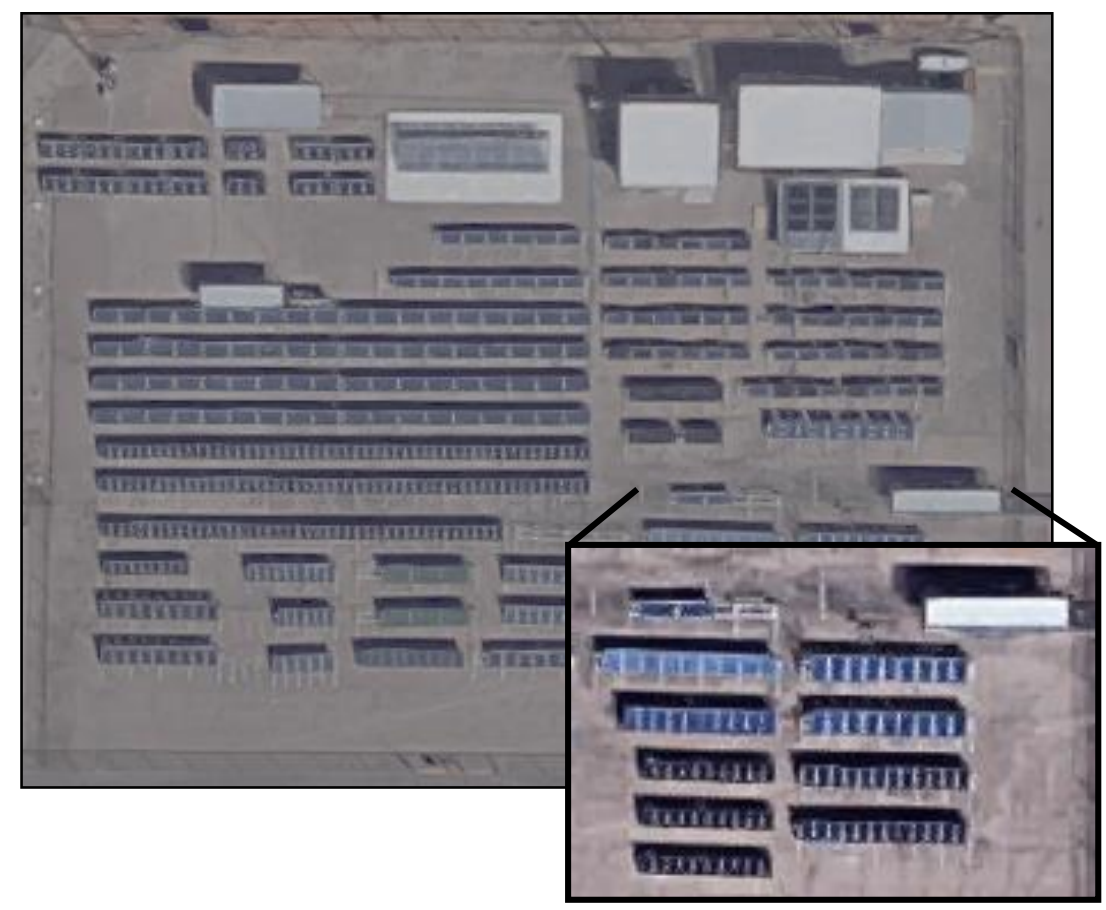

Figure 2: Ariel view of AzRISE/TEP test yard with the Zone 1 array emphasized.

Additional improvements to the legacy system have focused on upgraded sensors for DC and AC current and voltage measurements. Homemade shunt resistors were used previously to measure current throughout the test yard and these have been replaced by environmentally robust manganin metal-alloy resistance elements for temperature stability. These shunts offer a four-wire connection to provide the measurement of the shunt's voltage drop and they meet military specifications for accuracy. The shunts can continuously measure up to 66 amps and feature a phenolic base mount. Figure 3 pictures both the legacy and the improved devices.

Further, upgrades to DC voltage measurements, performed using a simple voltage divider at 100:1 ratio, utilized precision resistors, which have a $2 \%$ tolerance, heat resistance, and are rated at a half watt. Finally, an additional stage of AC metering was required to observe inverter efficiencies. Magnelab SPT-0375 series transformers, which are 
compatible with the upgraded data loggers, were installed to provide a linear output voltage proportional to the input voltage.
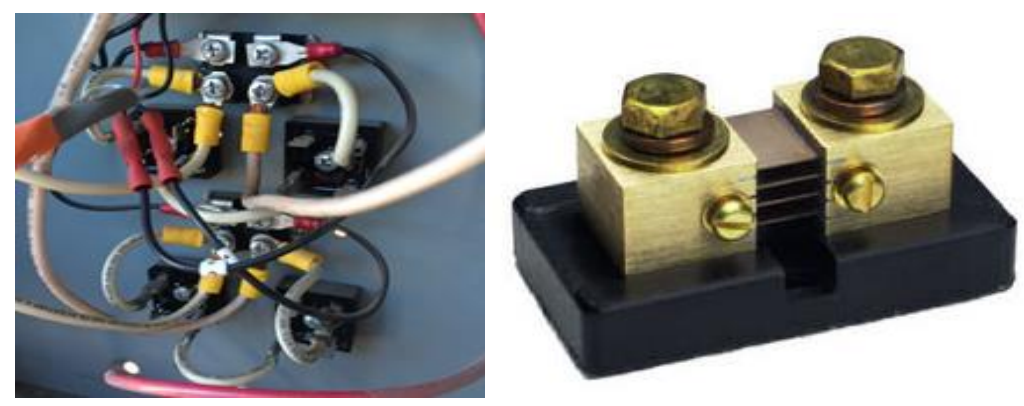

Figure 3: In-house-constructed current shunts (two pictured, left) and CSR-100 current shunt resistor (right).

\section{EXPERIMENTAL METHODS}

Initial data collection system evaluation is currently underway. To-date, tests have been performed both to establish basic DC-data collection accuracy and fidelity from an operating string and also to confirm system insensitivity to channel cross-talk under AC or spurious noise signal conditions as the refurbishment extends to AC data collection.

Experiments were conducted to compare the reliability and quality of the data that the updated instrumentation provided in comparison to the older equipment. A string of 7 polycrystalline silicon panels were connected in series and a Campbell Scientific CR1000 was used to record the voltage. The data logger was powered by a battery which in turn was fed by an AC inverter. This was done for two reasons: to smooth any AC ripple ${ }^{[9]}$ and to act as a universal power supply in the event of a failure. The output voltage of the string of solar modules was roughly $360 \mathrm{~V}$. This was too high to measure directly with the Campbell Scientific CR1000, which has a maximum input voltage of $\pm 8 \mathrm{~V}$. To get around this, a $1 \%$ voltage divider using a $200 \mathrm{k} \Omega$ resistor and a $2 \mathrm{k} \Omega$ resistor was utilized. The stepped down voltage was

approximately $360 \mathrm{mV}$ which the Campbell could read adequately ${ }^{[10,11]}$. Care was taken to ensure that the whole system was properly grounded.

\section{RESULTS AND DISCUSSION}

Data obtained both on the legacy system and on the upgraded system are presented in Figures 4 and 5, below. An examination of the data in Figure 4, collected in July of 2014, clearly shows both daily intermittency and large, multiday, gaps in data. The periodic intermittency primarily resulted from dropped data strings during the course of a day, while the large data gaps, such as the one evident between $\sim 4000$ minutes and $\sim 6500$ minutes in the data in Figure 4 , occurred following a power interruption that shut down the data system. Such power interruptions are particularly common during summer monsoonal storms in southwestern Arizona. The inability of the instrumentation to automatically reset upon the restoration of power combined with the lack of internal memory data storage meant that data acquisition stopped and data was lost until the system was manually reset. 


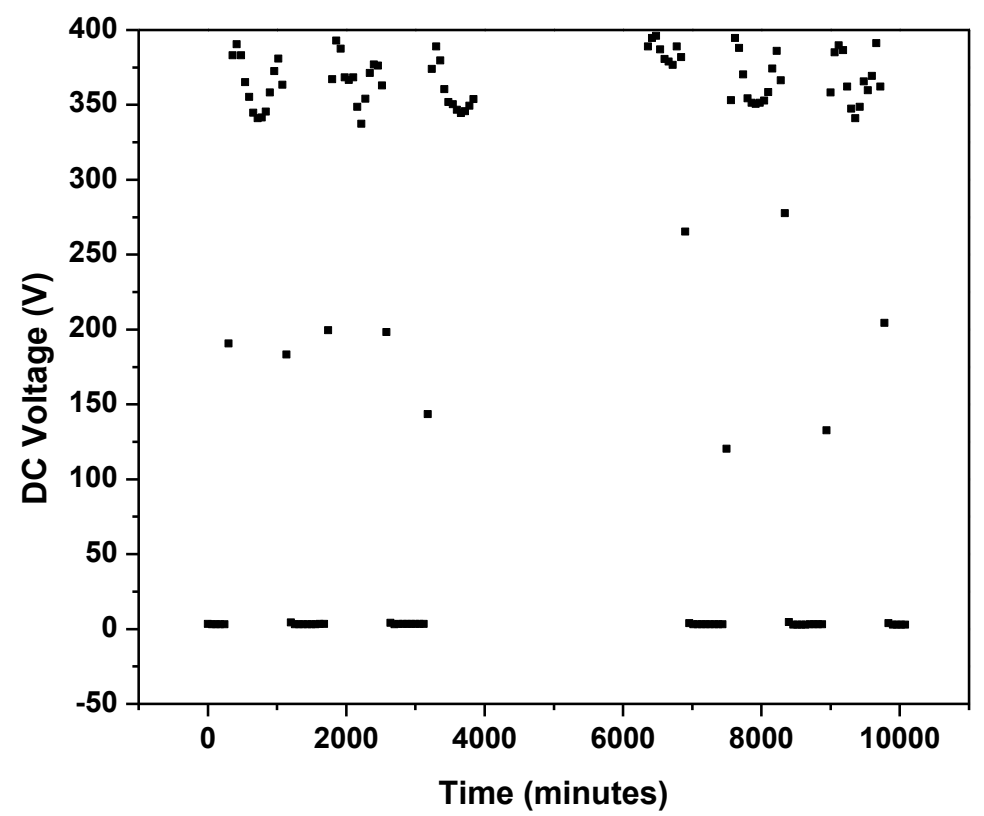

Figure 4: DC voltage readings from string of polysilicon PV modules using legacy equipment.

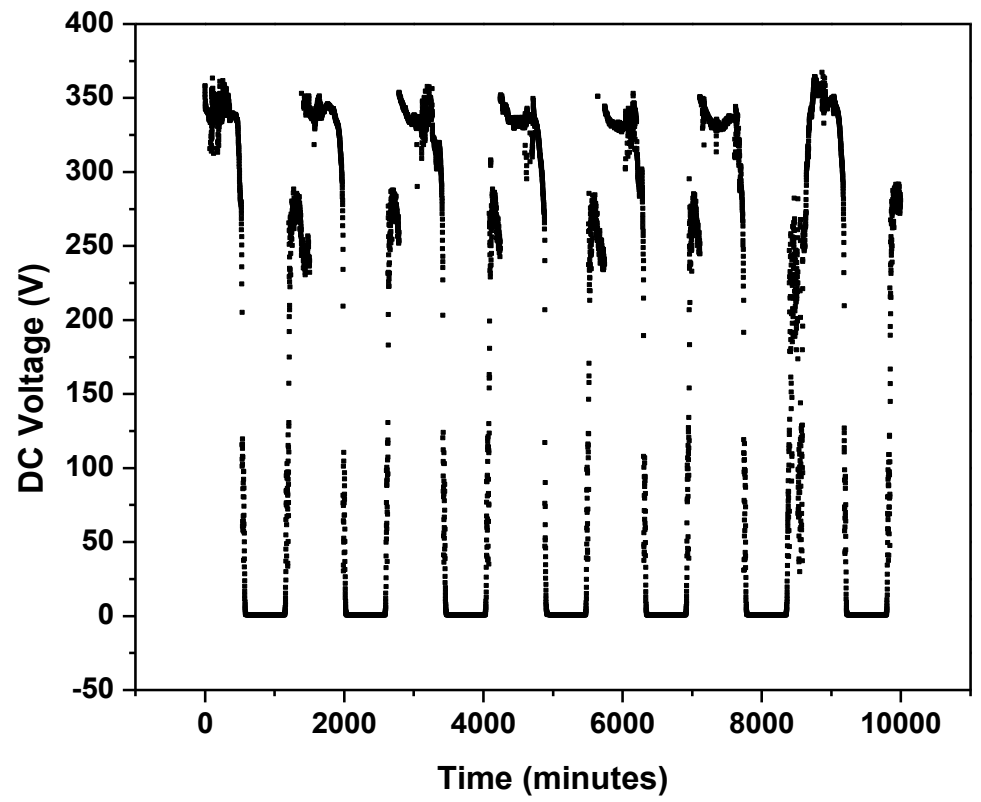

Figure 5: DC voltage readings from string of polysilicon PV modules using upgraded equipment.

By contrast, Figure 5 shows data collected during July/August 2016. A clear improvement in both data consistency and reliability is seen in the figure. The improved data resolution of Figure 5 reflects the one minute sampling interval and 
clearly contrasts the one hour interval used during collection of the legacy data in Figure 4. In addition, the new instrumentation does not exhibit any of the daily intermittency previously experienced, presumably a result of the overall instrumentation upgrades. Moreover, despite the fact that similar power interruptions occurred during the data cycle depicted in Figure 5 as in Figure 4, the backup power and data storage capacity of the new installation prevented the loss of data during the test cycle, leading to continuous and consistent data acquisition throughout the test sequence.

In addition to examples of improved data capabilities, experiments were also performed to investigate the impact of noise, cross talk, and grounding on data accuracy and precision. While those measurements are ongoing, one clear conclusion is that proper grounding is the most important precaution for voltage measurements with Campbell Scientific devices. Improper grounding clearly yielded data errors and significant inconsistencies. No evidence is seen of any cross talk between successive data channels in the data loggers or the multiplexers. These results are promising as the original planned use for the CR3000 was to monitor AC output from the inverters in conjunction with the DC inputs from the modules.

\section{CONCLUSION}

The upgrades to the test yard are working as designed and the data that has been gathered has shown the robustness and reliability of the new equipment. This is promising for the continued modernization of the test yard. The modularity of the hardware and ease of use make further upgrades feasible across the entirety of the yard. The enhanced data acquired from the test yard complements the University of Arizona's indoor testing facilities to reinforce the experimental results obtained at both locations.

\section{ACKNOWLEDGEMENTS}

This work was supported by the University of Arizona, the Arizona Research Institute for Solar Energy (AzRISE), and Tucson Electric Power.

\section{REFERENCE}

[1] Cronin, A. D., Brooks, A., Cormode, D., Hardesty, G., and Lonij, V. P. A., "Performance reviews from the Tucson Electric Power solar test yard," Proc. 37th IEEE PVSC, 2351-2356 (2011).

[2] Pulver, S., Cormode, D., Cronin, A., Jordan, D., Smith, R., "Measuring degradation rates of PV systems without irradiance data," Proc. 35th IEEE Photovoltaic Specialists Conference (PVSC), 001271 - 001276 (2010).

[3] Lai, T., Biggie, R., Brooks, A., Potter, Jr., B. G., and Simmons-Potter, K., "Environmental aging in polycrystalline-Si photovoltaic modules: Comparison of chamber-based accelerated degradation studies with field-test data," Proc. SPIE 9563, 956309-1 - 956309-8 (2015).

[4] Kurnik, J., Jankovec, M., Brecl, K., and Topic, M., "Outdoor testing of PV module temperature and performance under different mounting and operational conditions," Solar Energy Materials and Solar Cells, 95, 373-376 (2011).

[5] Spena, A., Cornaro, C., and Serafini, S., "Outdoor ESTER test facility for advanced technologies PV modules," Proc. 33rd IEEE Photovoltaic Specialists Conference (PVSC), 1-5 (2008 ). 
[6] Thakkar, N., Cormode, D., Lonij, V. P., Pulver, S., and Cronin, A. D., "A simple non-linear model for the effect of partial shade on PV systems," Proc. 35th IEEE Photovoltaic Specialists Conference (PVSC), 002321-002326 (2010).

[7] Kurtz, S. R., Myers, D., Townsend, T., Whitaker, C. , Maish, A., Hulstrom, R., Emery, K., "Outdoor rating conditions for photovoltaic modules and systems," Solar Energy Materials \& Solar Cells 62, 379-391 (2000).

[8] Biggie, R., Lai, T., Huang, W.-J., Potter, Jr., B. G., and Simmons-Potter, K., "Comparison of environmental degradation in Hanwha $295 \mathrm{~W}$ and SunPower $320 \mathrm{~W}$ photovoltaic modules via accelerated lifecycle testing," Proc. SPIE 9179, 917906-1 - 917906-9 (2014).

[9] Fang, P., White, B., Fiorentino, C., and Liu, Y.-F., "Zero ripple single stage AC-DC LED driver with unity power factor," Proc. 2013 IEEE Energy Conversion Congress and Exposition, 3452-3458 (2013).

[10] Mukaro, R. and Carelse, X. F., "A microcontroller-based data acquisition system for solar radiation and environmental monitoring," IEEE Transactions on Instrumentation and Measurement, 48, 1232-1238 (1999).

[11] Wilcox, S. and Stoffel, T., "Solar Resource and Meteorological Assessment Project (SOLRMAP)-Solar and Meteorological Station Options: Configurations and Specifications," NREL Specification December 12, 2008. 